\title{
Role of antenatal care in reducing incidence of eclampsia in eastern Uttar Pradesh, India
}

\author{
Babita Kapoor*, Namrata Verma, Reena Shrivastava
}

Department of Obstetrics and Gynecology, Baba Raghav Das Medical College, Gorakhpur, Uttar Pradesh, India

Received: 02 February 2019

Accepted: 01 April 2019

*Correspondence:

Dr. Babita Kapoor,

E-mail: babitakapoor1971@gmail.com

Copyright: () the author(s), publisher and licensee Medip Academy. This is an open-access article distributed under the terms of the Creative Commons Attribution Non-Commercial License, which permits unrestricted non-commercial use, distribution, and reproduction in any medium, provided the original work is properly cited.

\begin{abstract}
Background: Eclampsia is characterized by sudden onset of generalized tonic-clonic convulsions or coma in pregnancy or postpartum. It is a major cause of maternal and perinatal morbidity and mortality in developing countries. This study was conducted to determine the incidence of eclampsia and role of antenatal care in reducing the incidence.

Methods: This was a prospective study (July 2015-June 2016) conducted in labour room of department of obstetrics and Gynecology, BRD Medical college, Gorakhpur, Uttar Pradesh, India. A total no. of 141 women presenting with eclampsia were included in the study. Risk factors like antenatal care and sociodemographic status were studied for their role in increased incidence of eclampsia.

Results: There were 141 eclampsia cases out of 3536 deliveries, during the study period. The incidence of eclampsia was found to be $4 \%$. Out of 141 eclampsia cases $35.5 \%$ did not receive any antenatal care. $56.7 \%$ received substandard care in less than 4 antenatal visits. Out of those who received antenatal care (91/141), 67\% received irregular, substandard care in primary health centre of their locality. Majority of eclampsia cases were between 16-25 years of age $(85.1 \%)$ and were primigravida $(62.4 \%)$. Majority of eclampsia cases were uneducated $(89.4 \%)$, of lower socioeconomic status $(71.4 \%)$ and belonged to rural area $(67.4 \%)$.

Conclusions: High incidence of eclampsia in B.R.D. Medical College reflects the status of eclampsia in eastern Uttar Pradesh, India. To prevent eclampsia our health care centres should be strengthened by well trained medical officers, other health care workers and adequate antenatal care facilities.
\end{abstract}

Keywords: Antenatal care, Eclampsia, Preeclampsia

\section{INTRODUCTION}

Eclampsia is an extremely severe form of preeclampsia. It is characterized by sudden onset of generalized tonicclonic convulsions or coma in pregnancy or postpartum, unrelated to other cerebral conditions in patients with signs and symptoms of preeclampsia. ${ }^{1}$ According to revised definition, Preeclampsia is hypertension after 20 weeks of gestation with one or more of the following: proteinuria, maternal organ dysfunction including renal, hepatic, hematological or neurological complications or foetal growth restriction. ${ }^{2}$ Eclampsia can manifest itself in unusual and unpredictable manner in well monitored patients without risk factors. The diagnosis must be made quickly for taking urgent and appropriate obstetric management. ${ }^{3}$ Almost all cases $(91 \%)$ of eclampsia develop at or beyond 28 weeks. ${ }^{4}$ Eclampsia occurring before the $20^{\text {th }}$ week of gestation has usually been reported with molar or hydropic degeneration of the placenta, with or without a coexistent fetus. ${ }^{5,6}$ It can occur during antepartum (38-53\%), intrapartum (18-36\%) or in post partum period (11-44\%)., ${ }^{4,8}$ Approximately 1 in 
2000 deliveries $(0.05 \%)$ is complicated by eclampsia in developed countries, whereas the incidence in developing countries varies from 1 in 100 to 1 in 1700 cases. ${ }^{7,9}$ The rate of preeclampsia and eclampsia is higher in the developing countries because of absent prenatal care and lack of access to proper hospital care. ${ }^{10}$ In India reported incidence of eclampsia varies from 0.179 to $3.7 \% .^{10-12}$ According to WHO report 2008 eclampsia accounts for $12 \%$ of all maternal deaths in developing countries. ${ }^{13}$ Maternal mortality in eclampsia is very high in India and varies from $2-30 \%$, much more in rural hospitals than in urban counterpart. ${ }^{14}$ Hypertensive disease in pregnancy complicated by Preelampsia/ eclampsia requires proper antenatal care, early recognition and referral, adequate treatment and timely delivery. ${ }^{15}$ Clear protocols for management of hypertension in pregnancy at all levels of health care are required for better maternal as well as perinatal outcome. ${ }^{15}$

The present study was conducted in B.R.D Medical College, Gorakhpur, to know the incidence of eclampsia and role of antenatal care along with sociodemographic variables in reducing incidence of eclampsia in eastern Uttar Pradesh.

\section{METHODS}

This prospective clinical study was conducted over a period of one year from July 2015 to June 2016, in the labour room of department of obstetrics and gynaecology of Baba Raghav Das (B.R.D) Medical College, Gorakhpur, Uttar Pradesh, India. A total no. of 141 women presenting with eclampsia were included in the study. At the time of admission of eclampsia patients, Proper history was taken from her guardian regarding age, parity, residence, nearby health care centres, distance from our institution, education, living status, no of antenatal visits, awareness about preeclampsia/eclampsia, and facilities at health care centres like B.P. monitoring, urine analysis etc. Complete clinical examination including general and obstetric was done. Eclampsia patients were managed according to the hospital protocol for eclampsia management, by judicious use of antihypertensive (labetalol), anticonvulsant (magnesium sulphate) etc. and obstetric interference in the form of induction of labour or caesarean section. Data were analyzed for incidence, antenatal care and sociodemographic variables.

\section{Operational definitions}

Eclampsia- Women with gestational age $>20$ weeks, BP more than or equal to140/90 $\mathrm{mm}$ of hg with convulsions or coma with either urine protein $>=+1$ or thrombocytopenia (<100000/micro litre), impaired liver functions (liver enzymes raised to twice normal concentration), renal insufficiency (serum creatinine $>1.1 / \mathrm{dl}$ ), pulmonary oedema, new onset cerebral or visual disturbances.
Regular antenatal care- At least 4 or more check up by an authorized service provider.

Irregular antenatal care- Less than 4 antenatal check-up by an authorized service provider. No antenatal careTotal absence of antenatal check up.

Standard antenatal care- $>8$ antenatal care with regular BP monitoring and urine analysis for protein with use of magnesium sulphate for severe preeclampsia, imminent eclampsia and eclampsia.

Socioeconomic status (SES)- SES was categorised based on Kuppuswamy's socioeconomic scale (2012), into Upper, Upper Middle, Lower Middle, Upper Lower and Lower Socioeconomic class.

\section{RESULTS}

During the study period (July 2015-June 2016), 141 eclampsia cases found among 3536 deliveries. The incidence of eclampsia was $4 \%$ of the total deliveries in our study (Figure 1).

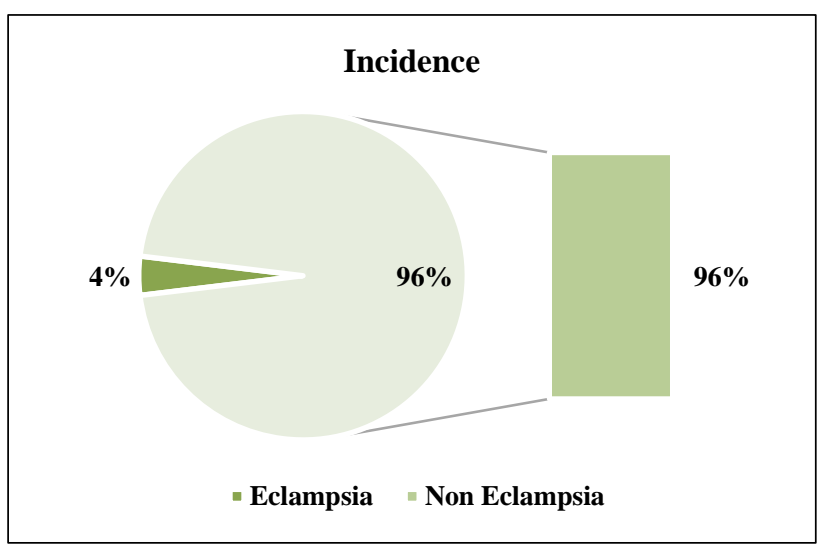

Figure 1: Incidence of eclampsia in present study (July 2015-June 2016).

Table 1: Number of antenatal visits in eclampsia cases.

\begin{tabular}{|lll|}
\hline $\begin{array}{l}\text { No of antenatal } \\
\text { visits }\end{array}$ & $\begin{array}{l}\text { Eclampsia cases } \\
(\text { no. })\end{array}$ & $\begin{array}{l}\text { Percentage } \\
(\%)\end{array}$ \\
\hline 0 & 50 & $35.5 \%$ \\
\hline $1-<4$ & 80 & $56.7 \%$ \\
\hline$>=4$ & 11 & $7.8 \%$ \\
\hline
\end{tabular}

Table 2: Health care centres used for antenatal care.

\begin{tabular}{|lll|}
\hline Health care centre & $\begin{array}{l}\text { Eclampsia } \\
\text { cases (no.) }\end{array}$ & $\begin{array}{l}\text { Percentage } \\
(\%)\end{array}$ \\
\hline Primary health care & 61 & $67 \%$ \\
\hline Secondary health care & 29 & $31.9 \%$ \\
\hline Tertiary health care & 01 & $1.1 \%$ \\
\hline
\end{tabular}


Out of 141 eclampsia cases, $50(35.5 \%)$ patients had no antenatal care. 80 cases $(56.7 \%)$ had inadequate care i.e. less than 4 antenatal visits. Only 11 cases $(7.8 \%)$ received antenatal care more than 4 times (Table 1). It shows that majority of eclampsia patients received inadequate antenatal care followed by those who didn't receive any antenatal care. Out of those who received antenatal care $(91 / 141)$, most of them $61(67 \%)$ had their antenatal care at primary health centre. $29(31.9 \%)$ received antenatal care at secondary health care centre. Only 1 patient received antenatal care at tertiary care centre (Table 2 ). In our study $61(43.3 \%)$ eclampsia cases were in the age group 16-20 years, 59 (41.8\%) were between $21-25$ years of age. 16 cases $(11.4 \%)$ were between $26-30$ years and only 5 cases $(3.5 \%)$ were between $31-35$ years of age. There was no case above 35 years of age. This study shows that majority of eclampsia patients i.e.120/141 $(85.1 \%)$ were in the younger age group between 16 to 25 years (Table 3).

Table 3: Age distribution in eclampsia cases.

\begin{tabular}{|lll|}
\hline Age (in years) & Eclampsia cases (no.) & $\%$ \\
\hline $16-20$ & 61 & 43.3 \\
\hline $21-25$ & 59 & 41.8 \\
\hline $26-30$ & 16 & 11.4 \\
\hline $31-35$ & 05 & 3.5 \\
\hline
\end{tabular}

Table 4: Parity distribution in eclampsia cases.

\begin{tabular}{|lll|}
\hline Parity (no.) & Eclampsia cases (no.) & $\%$ \\
\hline 0 & 88 & 62.4 \\
\hline $1-4$ & 46 & 32.6 \\
\hline$>=5$ & 07 & 4.96 \\
\hline
\end{tabular}

Table 5: Sociodemographic variables in eclampsia.

\begin{tabular}{|lll|}
\hline Variables & Eclampsia cases (no.) & $\%$ \\
\hline Demography & & \\
\hline Rural & 95 & 67.4 \\
\hline Urban & 46 & 32.6 \\
\hline Educational status & & \\
\hline Educated & 15 & 10.6 \\
\hline Uneducated & 126 & 89.4 \\
\hline Socioeconomic status & & \\
\hline Upper & 0 & 0 \\
\hline Upper middle & 2 & 1.4 \\
\hline Lower middle & 2 & 1.4 \\
\hline Upper lower & 37 & 26.2 \\
\hline Lower & 100 & 71 \\
\hline
\end{tabular}

Most of the eclampsia patients i.e. 88/141 (62.4\%) were primigravida, $46(32.6 \%)$ patients were multigravida and only $7(4.96 \%)$ were grand multipara (Table 4). Majority of eclampsia patients, 95/141 (67.4\%) belonged to rural area, $46(32.6 \%)$ belonged to urban area. Most eclampsia patients $126 / 141(89.4 \%)$ were uneducated. In this study majority of patients $(71 \%)$ belonged to lower socioeconomic class according to Kuppuswamy socioeconomic scale. 37 cases $(26.2 \%)$ were from upper lower socioeconomic status. No eclampsia patient belonged to upper class.

Table 6: Incidence of eclampsia in various studies.

\begin{tabular}{|c|c|c|}
\hline Study & Place of study & Incidence \\
\hline Douglas KA et al ${ }^{7}$ & United Kingdom & $0.05 \%$ \\
\hline Shaikh SB et al ${ }^{16}$ & Andhrapradesh, India & $0.58 \%$ \\
\hline Sunita $\mathrm{TH}$ et $\mathrm{al}^{17}$ & Karnataka, India & $0.7 \%$ \\
\hline Manjusha $\mathrm{S}$ et al ${ }^{18}$ & Maharashatra, India & $1.63 \%$ \\
\hline Singh $\mathrm{S}$ et al ${ }^{19}$ & Orissa, India & $3.2 \%$ \\
\hline Babbar $\mathrm{K}$ et $\mathrm{al}^{20}$ & $\begin{array}{l}\text { Bilaspur, } \\
\text { Chhattisgarh, India }\end{array}$ & $3.5 \%$ \\
\hline Present study & Gorakhpur, India & $4.0 \%$ \\
\hline
\end{tabular}

\section{DISCUSSION}

Present study was conducted in the labour room of obstetrics and Gynaecology department of B.R.D.Medical college, Gorakhpur, Uttar Pradesh, India. Gorakhpur is a Tehsil/block in the Gorakhpur district of Uttar Pradesh. It comes in eastern Uttar Pradesh (Purvanchal). Total area of Gorakhpur is $840 \mathrm{~km}^{2}$ including $674.25 \mathrm{~km}^{2}$ rural area and $165.90 \mathrm{~km}^{2}$ urban areas. B.R.D. Medical College is the only tertiary care centre of eastern Uttar Pradesh. It caters patients not only from Gorakhpur district but also from surrounding districts and districts of Bihar and Nepal border. Purpose of the study is to highlight the impact of lack of antenatal care and sociodemograhically associated problems, on increased incidence of eclampsia in eastern Uttar Pradesh.

In our study, the incidence of eclampsia was $4 \%$ (141/3536 deliveries) which is higher than incidence reported from other states of India. The incidence is much higher than that of developed countries like the United Kingdom, where eclampsia complicates $0.05 \%$ of total deliveries. ${ }^{7}$ The incidence is comparable to other studies also. ${ }^{7,16-20}$ (Table 6). The higher incidence in our study is because of high referral rate of eclampsia patients. Patients are referred from primary health centres, secondary health centres and also from private hospitals. However this incidence does not reflect true incidence because our data are all our hospital based. There are so many hidden eclampsia cases that died in remote rural areas without diagnosis or sometimes these eclampsia cases died on the way before reaching our tertiary care centre. To know this number, proper documentation of antenatal patients is required in each and every health care centre.

In the present study, $35.5 \%$ eclampsia patients did not receive any antenatal care Majority i.e. $56.7 \%$ received irregular and inadequate care (<4 visits) and only $7.8 \%$ received regular antenatal care $(>=4)$. Lack of antenatal care and irregular antenatal care both are important risk 
factors for increased incidence of eclampsia. This is also supported by various studies conducted in India as well as other developing countries. In a study conducted by Prabhakar G et al, $79.67 \%$ eclampsia patients did not have any antenatal care or received inadequate care with less than three antenatal visits. ${ }^{21}$ According to study conducted by Sunita $\mathrm{TH}$ et al, $45 \%$ patients had no antenatal care and around $55 \%$ patients had some sort of antenatal care. ${ }^{17} 93.99 \%$ patients had no ANC as per S. Jain et al and $76.66 \%$ had no ANC as per S. Swain et al. ${ }^{22,23}$ As per Sarma HK et al, $68.33 \%$ had history of irregular antenatal care. ${ }^{24}$

In New Zealand eclampsia was a notifiable disease for many years, and its incidence declined from 32/10000 to 8/10000 between1928-33 and 1956-8, due to the advent of routine screening for early signs of preeclampsia. The reduction in the incidence of eclampsia in the United Kingdom between the1920s and 1970s also occurred as antenatal care become universally available. ${ }^{25}$ In developed countries the incidence of eclampsia is significantly low because of uniform health care policy and comprehensive antenatal care with early detection of preeclampsia and its management. ${ }^{26}$ This together with the fact that countries without effective antenatal screening programmes still have much higher incidence provides evidence in favour of standard antenatal care.

Tuffnel DJ et al, suggested that adequate antenatal care facilitates early identification of risk factors and appropriate intervention to prevent progression to eclampsia. ${ }^{27} 7.8 \%$ eclampsia cases in our study had $>4$ antenatal visits despite that they develop eclampsia. The reasons were substandard antenatal care, negligence from patient side and atypical eclampsia (non-classical). WHO Secondary Analysis, 2014, found >8 antenatal visits as protective factor for preeclampsia/eclampsia when compared with 4-8 visits. $^{28}$

Out of those who received antenatal care (91/141), 67\% received care from primary health centre, $31.9 \%$ received care from secondary health centre and only 1 patient received antenatal care from our hospital. Care below expectation in the primary health establishment is a disturbing factor as evident from report of National Eclampsia Registry that only $44 \%$ of eclampsia prevention with magnesium sulphate before admission to hospital. $^{29}$ Besides no of antenatal care quality of antenatal care is also important for reducing no. of eclampsia.This also indicates a severe need to train medical officers, birth attendants and paramedical personnel in remote interiors. ${ }^{29}$

In our study most cases of eclampsia $(85.1 \%)$ were young $<25$ years of age and primigravida $(62.4 \%)$. This is comparable to other studies in India. ${ }^{16-18,20}$ High number of adolescents in our study reflect early age at marriage which renders a very young population of women at risk of morbidity \& mortality. First time pregnant women is an important high risk factor as Pregnancy is a stressful condition that could unmask several conditions because of this, first time pregnant women need regular and compulsory screening.

In Gorakhpur district, of 6.93 lakhs population $81.17 \%$ live in rural areas. In our study $67.4 \%$ eclampsia patients belonged to rural areas. This is one of the biggest reasons of substandard antenatal care and increase incidence of eclampsia in eastern Uttar Pradesh In rural areas of eastern Uttar Pradesh, there is lack of well trained medical officers, specialist doctors, health care workers and proper medical facilities. These factors are responsible for substandard antenatal care. In our study $89.4 \%$ eclampsia patients were uneducated. The literacy of mother plays important role in developing eclampsia. This is also proven by various studies. ${ }^{20,24,28} 71 \%$ eclampsia patients belonged to lower socioeconomic status. Lack of education, low socio economic status lack of access and awareness to medical care are the important factors in development of eclampsia as quoted by various studies. ${ }^{16,17,20,24}$

\section{CONCLUSION}

High incidence of eclampsia in our hospital reflects the status of eclampsia in eastern Uttar Pradesh, India. As we know eclampsia usually follows Preeclampsia, to prevent eclampsia, preeclampsia has to be prevented. To prevent eclampsia our health care centres should be strengthened by well trained medical officers, health care workers and adequate antenatal care facilities. There should be periodic training of all medical officers and health care personnel regarding proper and early management of preeclampsia/eclampsia and to handle obstetric emergencies.

Transport facilities should be there in each and every health centre. Antenatal women and their guardians should be counselled about early and regular antenatal care during pregnancy.

Awareness regarding preeclampsia/eclampsia should be created by health personnels. Antenatal women should be advised to come to the health centre immediately if any symptom of the disease arises. By using these simple measures we can reduce a heavy burden of eclampsia in our locality.

\section{ACKNOWLEDGMENTS}

Authors would like to extend his sincere gratitude to all those who helped us in completing this study especially all patients, post graduate students and Head of the department of obstetrics and Gynaecology, B.R.D. Medical College, Gorakhpur, Uttar Pradesh, India.

\section{Funding: No funding sources}

Conflict of interest: None declared

Ethical approval: The study was approved by the Institutional Ethics Committee 


\section{REFERENCES}

1. Bansal V, Kaizad R. Damania. Hypertensive disorders in Pregnancy. Arias, Practical Guide to high risk pregnancy and delivery, A South Asian Perspective, $4^{\text {th }}$ Ed.; 2015:185-232.

2. Tranquilli AL, Brown MA, Zeeman. The definition of severe and early onset preeclampsia. Statements from the International Society for the study of Hypertension in Pregnancy (ISSHP). Pregnancy Hypertension. 2013;3(1):44.

3. Ducarme G, Herrnberger S. Eclampsia: retrospective study of 16 cases. Obs and gynaecology Fertility. 2009;37(1):11-7.

4. Matter F, Sibai BM. Eclampsia. VIII Risk factors for maternal morbidity. Am J Obstet Gynecol. 2000;182:307-12.

5. Sibai BM, Abdella TH, Taylor HA. Eclampsia in the first half of pregnancy: a report of three cases and review of the literature. J Reprod Med. 1982;27:7068.

6. Newman RB, Eddly GL. Association of eclampsia and hydatidiform mole: case report and review of the literature. Obstet Gynecol Surv. 1988;43:185-90.

7. Douglas KA, Redman CW. Eclampsia in the United Kingdom. BMJ. 1994;309:1395-400.

8. Katz VL, Farmer R, Kuller J. Preeclampsia into eclampsia: toward a new paradigm. Am J Obstet Gynecol. 2000;182:1389-96.

9. World Health Organization. International Collaborative Study of Hypertensive Disorders of Pregnancy. Geographic variation in the incidence of hypertension in pregnancy. Am J Obstet Gynecol. 1988; 158:80-3.

10. Goldenberg RL, McClure E, MacGuire ER. Lessons for low income regions following the reduction in hypertension- related maternal mortality in high income countries. Int $\mathrm{J}$ Gynecol Obstet. 2011;113:91-5.

11. Vanawalla NY, Ghamande S. A five year analysis of eclampsia. J Obstet Gynecol India. 1989;39:513-5.

12. Suman G, Somegowda S. Maternal and perinatal outcome in Eclampsia in a District Hospital. J Obstet Gynecol India. 2007;57:324.

13. Educational material for teachers of midwifery. World Health Organization, 2nd edition, 2008:1-131.

14. Dutta DC. Hypertensive disorders in pregnancy. Konar H, editor. Text book of obstetrics, $7^{\text {th }}$ Ed.; New Central Book Agency (P) Ltd: Kolkata; 2011:2019-40.

15. Ghulmiyyah L, Sibai B, Maternal mortality from Preeclampsia/Eclampsia. Seminar Perinatol. 2012;36(1):56-9.
16. Shaikh SB. A study on maternal and perinatal out comes in cases of eclampsia admitting to government medical college and general hospital, Anantapuramu, Andhra Pradesh, India. Int J Reprod Contracept Obstet Gynecol. 2016;5(7):2146-50.

17. Sunita TH, Desai RM. Eclampsia in a teaching hospital: Incidence, clinical profile and response to magnesium sulphate by Zuspan's regimen. IOSR J Dent Med Scien. 2013;4(2):1-5.

18. Manjusha S, Vandana N. Eclampsia: A retrospective study in a tertiary care centre. Indian $\mathrm{J}$ Pharma Practi. 2013;6(1):69-73.

19. Singh S, Behera A. Eclampsia in Eastern India: Incidence, Demographic Profile and response to three different anticonvulsant regimes of magnesium Sulphate. The Internat J Gynecol Obstet. 2010;15(2).

20. Babbar K. Burden of eclampsia: a persisting problem in the developing countries Int J Reprod Contracept Obstet Gynecol. 2015:4(4):1029-33.

21. Prabhakar G, Shinde MA, Jadhav CA. Clinical study of eclampsia patients at DR V M. Government Medical College, Sholapur, India. IOSR J Dent Medi Scien. 2015;13(7):10-6.

22. Jain S, Nager S. Maternal mortality from eclampsia, a critical analysis of 693 cases in two teaching hospitals in Northern India. 1998;38:256-60.

23. Wain S, Ojha KL. .Maternal and perinatal mortality due to Eclampsia. Indian Paedia J. 1993:30(6):771-3.

24. Sarma HK, Talukdar B. Eclampsia: a clinical prospective study in a referral hospital. J Obstet Gynaecol Barpeta. 2014;1(1):57-61.

25. Corkill TF. Experience of toxaemia control in Australia and New Zealand. Pathol Microbiol. 1961;24:428-34.

26. Aparna Khan. Analysis of the causes of maternal death in eclampsia. IOSR J Den Med Scien. 2014;13:7-10.

27. Tuffnel DJ, Jankowisz D. Outcomes of severe preeclampsia/eclampsia in Yorkshire 1999/2003. BJOG:An Int J Obstet Gynaecol. 2005;112(7):87580.

28. Bilano VL, Ota E. Risk Factors of PreEclampsia/Eclampsia and its Adverse Outcomes in Low and Middle- income Countries: A WHO Secondary Analysis. PLoS ONE. 9(3):e91198.

29. Gupta S, Wagh G. Preeclampsi-Eclampsia. J Obstet Gynecol India. 2014;64:1.

Cite this article as: Kapoor B, Verma N, Shrivastava $\mathrm{R}$. Role of antenatal care in reducing incidence of eclampsia in eastern Uttar Pradesh, India. Int J Reprod Contracept Obstet Gynecol 2019;8:1884-8. 